This item was submitted to Loughborough's Research Repository by the author.

Items in Figshare are protected by copyright, with all rights reserved, unless otherwise indicated.

\title{
Methodological troubles as problems and phenomena: ethnomethodology and the question of 'method' in the social sciences
}

PLEASE CITE THE PUBLISHED VERSION

http://dx.doi.org/10.1111/1468-4446.12136

\section{PUBLISHER}

(c) Wiley

VERSION

AM (Accepted Manuscript)

\section{PUBLISHER STATEMENT}

This work is made available according to the conditions of the Creative Commons Attribution-NonCommercialNoDerivatives 4.0 International (CC BY-NC-ND 4.0) licence. Full details of this licence are available at: https://creativecommons.org/licenses/by-nc-nd/4.0/

\section{LICENCE}

CC BY-NC-ND 4.0

\section{REPOSITORY RECORD}

Greiffenhagen, Christian, Michael Mair, and Wes Sharrock. 2019. "Methodological Troubles as Problems and Phenomena: Ethnomethodology and the Question of 'method' in the Social Sciences". figshare. https://hdl.handle.net/2134/18086. 


\section{Methodological Troubles as Problem and Phenomenon: Ethnomethodology and the Question of 'Method' in the Social Sciences}

\section{Christian Greiffenhagen, Michael Mair, Wes Sharrock}

\section{Version}

March 23, 2015

\section{Abstract}

Across the disciplinary frontiers of the social sciences, studies by social scientists treating their own investigative practices as sites of empirical inquiry have proliferated. Most of these studies have been retrospective, historical, after-the-fact reconstructions of social scientific studies mixing interview data with the (predominantly textual) traces that investigations leave behind. Observational studies of in situ work in social science research are, however, relatively scarce.

Ethnomethodology was an early and prominent attempt to treat social science methodology as a topic for sociological investigations and, in this paper, we draw out what we see as its distinctive contribution: namely, a focus on troubles as features of the in situ, practical accomplishment of method, in particular, the way that research outcomes are shaped by the local practices of investigators in response to the troubles they encounter along the way. Based on two case studies, we distinguish methodological troubles as problems and methodological troubles as phenomena to be studied, and suggest the latter orientation provides an alternate starting point for addressing social scientists' investigative practices.

\section{Keywords}

methodology; method; ethnomethodology; qualitative; quantitative; science and technology studies 


\section{Introduction}

Over the last two decades, and across the disciplinary boundaries of the social sciences, studies by social scientists treating their own investigative practices as sites of empirical inquiry have proliferated. This trend towards disciplinary self-study, i.e. studies of social scientists by social scientists, has intensified with work, inter alia, on the sociology of social scientific knowledge (Maynard and Schaeffer 2000; Leahey 2008), genealogical histories of social research techniques (Abbot 2001; Osborne, Rose, and Savage 2008), studies of the production of 'social knowledge' (Camic, Gross, and Lamont 2011; Saetnan, Lomell, and Hammer 2011), and investigations of 'the social life of methods' (Law, Ruppert, and Savage 2011; Savage 2013). Consequently, we now have studies of, for example, social science infrastructures and disciplinary lineages (Abbott 2001), the survey (Law 2009; Osborne and Rose 1999), the census (Ruppert 2007), the interview (Briggs 2007; Savage 2010), the map and the model (Osborne and Rose 2004), the art of measurement and statistical manipulation (Espeland and Stevens 2008; Saetnan, Lomell, and Hammer 2011), fieldwork (Gupta and Ferguson 1997; Gieryn 2006), as well as of processes of professional review, judgment and evaluation (Lamont 2009; Camic, Gross, and Lamont 2011).

It would be misleading to construe these as signifying a problematic introversion, indicative of malaise, paralysis or crisis (though an element of this is perhaps in play, see Savage and Burrows 2007). Not only does this work reflect growing interest in practices and techniques of knowledge making in social and cultural life more broadly, and not just science and administration (see Majima and Moore 2009; Benzecry and Krause 2010), it also reflects dissatisfaction with programmatic doctrinal statements of the aims of the social sciences wedded to meta-reflection, critique and inter- and intra-disciplinary jostling and oneupmanship. Rather than using idealized conceptions of social science as decontextualized standards to judge what social scientists do, the focus has been on understanding the scale, range and diversity of the social sciences practical entanglements in social and cultural life, showing that the social sciences do not merely record, but are productive, helping to bring into being and stabilize the very phenomena they depict, thereby establishing open-ended, coconstitutive, reflexive and recursive relationships between what is studied and how (Lury and Wakeford 2012). Subject matter and method, on this reading, are thoroughly interdependent and mutually insinuating. 
The interest in examining the work of social fact production has not, however, translated into many direct studies of social scientists at work and their 'logics of practice' (Bourdieu and Wacquant 1992). The studies discussed above are mainly retrospective, historical, after-thefact reconstructions of social scientific studies assembled out of interview data, where available, and the (predominantly) textual-archival traces such investigations leave behind. While we take no issue with these approaches to 'problems' of method, we believe that investigations of in situ work in social science research, i.e., equivalents of the 'laboratory studies' of the natural sciences (Latour and Woolgar 1979; Lynch 1985) and mathematics (Greiffenhagen 2008, 2014), can provide a useful counterpart, indeed counterpoint, to them. Compared to the flourishing body of retrospective, historical-genealogical, and exegetical research that has been and is currently being conducted, however, there are far fewer studies of this kind.

The few observational studies of social scientists at work that have been conducted have largely focused on the interactional organisation of the interview, due primarily to its status as one of the lynchpins of social research both inside and outside the academic social sciences (Silverman 1973; Suchman and Jordan 1990; Maynard and Schaeffer 2000; Maynard et al. 2002; Roulston, DeMarrais and Lewis 2003). Beyond this, there have also been, for example, studies of 'data sessions’ (Olszewski, Macey and Lindstrom 2007; Antaki et al. 2008; Tutt and Hindmarsh 2011; Bushnell 2012), 'coding' (Goodwin 1994; Olszewski, Macey and Lindstrom 2007; Housley and Smith 2011), the scrutiny work of social science review boards (Stark 2011) and examinations of 'analysis’ (Konopasek 2008; Garforth 2012; and see Mair, Greiffenhagen and Sharrock 2013 for a more comprehensive overview of this area of research as a whole).

In ethnomethodology both these strands of inquiry are brought together: how a general interest in the role of method in the social sciences leads into studies of the practical achievements of both lay and professional sociological reasoning, has been a, if not the, central concern of ethnomethodology. In what follows, we therefore want to draw out what we see as the distinctive contribution of ethnomethodology to research in this area: namely, a focus on troubles as features of the in situ, practical accomplishment of method. Ethnomethodology retains an ongoing commitment to demonstrations of the specific ways research outcomes are shaped by the local practices of investigators in response to the troubles they encounter along the way. For ethnomethodology, troubles are normal in any 
practice, including the social sciences, but it is the distinctive forms they take from setting to setting that are of interest, providing wider insights into the practices in question. Put simply, to learn about troubles is to learn about the practices they are normal to.

Before going on to empirical studies of two specific cases, in the next section we want to outline the ethnomethodological interest in troubles in more depth. Our aim in doing so is less in contributing to debates on how sociological method might 'properly' be conceived, independently of what sociologists routinely get up to, than in contributing to contemporary debates on how 'methods work' might be studied - in saying something to those with an interest in sociological practice as a topic of empirical inquiry. In that sense, while we acknowledge the wider meta-analytical debates such work touches upon, as in debates about, e.g., the role method ought to play in the social sciences or the standards by which research ought to be judged - themselves perennial, unresolved and perhaps unresolvable sources of dispute - our concerns here are of a much more limited kind; namely, in what ways are sociological practices investigable? And it is in responding to this question that we think ethnomethodology has something valuable to offer, particularly in relation to a growing body of empirical studies of method that as yet shows limited awareness of how ethnomethodology might be relevant to its concerns.

\section{Ethnomethodology and troubles of method}

That ethnomethodology should take an interest in the investigative work of social scientists may come as a surprise to many. Ethnomethodology, particularly Garfinkel’s articulation of it, our primary focus here ${ }^{\mathrm{i}}$, is generally thought of as being profoundly sceptical about the social sciences, and is often associated with a series of arguments designed to demonstrate the impossibility of sociological research (Atkinson 1988: 450). There are several (not entirely undeserved) reasons as to why ethnomethodology has gained a reputation for being querulous and troublesome, particularly in relation to sociology, but matters are not as simple as they might first appear. As a way of setting the stage for the discussion that follows, we will concentrate on two aspects of ethnomethodology’s take on the social sciences here.

The first aspect is the steadfast refusal to privilege sociological perspectives on the social world. In treating ‘sociological reasoning' as a ubiquitous feature of everyday life, Garfinkel was not seeking to elevate sociology to the status of a universal science but to undermine 
attempts to draw a line of demarcation between sociological analyses and ordinary forms of practical reasoning by showing their thoroughly 'vulgar' grounding (Sharrock 2001; Lynch 2000). For Garfinkel, sociological reasoning, lay or professional, constituted a vernacular accomplishment, one which was embedded in, proceeded from and took-for-granted a heterogeneous patchwork of sense-making practices both ordinary and specialized. Like other aspects of everyday life, sociological reasoning too - the manner in which a world in common is made available through sociological work - was treated as a phenomenon amenable to study rather than the foundation upon which a 'science' could be built (see Hutchinson, Read and Sharrock 2008). Sociological practice was, therefore, seen as accountable in its details and explicable as such. Insofar as this led to attempts to specify how sociology could be made investigable as an 'assemblage' of practices, ethnomethodology both anticipated and helped set the scene for the current empirical 'turn to method'.

Secondly, and connected to the first, the abiding 'preference' in such studies was to begin with the host of 'troubles' that accompany attempts to arrive at (locally) 'adequate' accounts of the social world. For example, in Garfinkel's (1967:18-24) 'coding' study, graduate students were asked to code clinic records on patient intake and discharge according to fixed instructions. In a move repeated within contemporary empirical work on methods, rather than approach coding in straightforwardly instrumental terms, as a device for generating results, Garfinkel shifted attention to what was involved in coding-according-to-the-instructions. That is, Garfinkel was interested in investigating the 'actual activities' involved in following these instructions. In order to do this, Garfinkel enforced strict compliance with the instructions, urging the coders to use no other resource when making decisions about how any given item was to be coded. He found the coders were unable to make decisions on this basis while remaining confident that they were coding their materials correctly. The coders had both to work out what they were supposed to do to stick to the coding procedures and assess whether doing so captured the sense of the clinic files as records. The investigators did not (because they could not) operate on a strictly formal basis. Instead, they employed various ad hocing practices (such as 'et ceterea', 'unless', and 'let it pass') to fulfil what the instructions were talking about 'after all'. Rather than characterising these ad hoc responses to the troubles generated by strict adherence as flawed, Garfinkel insisted that they were essential and required for understanding the instructions in the first place: 
To treat instructions as though ad hoc features in their use were a nuisance, or to treat their presence as grounds for complaint about the incompleteness of instructions, is very much like complaining that if the walls of a building were only gotten out of the way one could see better what was keeping the roof up. (1967: 22)

Unsurprisingly, this focus on 'trouble-making' phenomena within the social sciences has often been interpreted as a way of making trouble for the social sciences (Garfinkel 2002). There is something to this. Nonetheless, despite 'sceptical' readings of ethnomethodology stemming from just such a view, as in Woolgar's (1988) derivation of a series of 'methodological horrors', there is more to the ethnomethodological concern with sociological troubles than this. For Garfinkel, it is not that social science cannot make reference to the world. The interesting question is rather how reference is achieved and achieved satisfactorily, practically speaking, something which involves looking in detail at the various decisions that social scientists have to make when working with their, often unpromising, materials.

For ethnomethodology, troubles and their management are, then, constitutive features of research practices in the social sciences. They are woven into the very fabric of social scientists' practices and the development of the forms of competence upon which they rest. Adapting Jordan and Fuller (1975), we might say that 'the problematic features of ... [the research situation] provide the raw materials for negotiating its hazards' (17) and 'though fraught with hazard ... [what is notable is that the research] does not, by and large, break down' (24). The presence of troubles and the production of the ad hoc, locally devised 'fixes' required to deal with them are not, therefore, the social sciences' 'dirty' secret but their praxeological grounds.

It is worth stressing this point, as it is liable to be misunderstood. For ethnomethodology, following Garfinkel, the specific troubles research throws up are not to be explained away as regrettable lapses on the part of individual researchers or used to impugn the work they do. Within ethnomethodology, focusing on the troubles that arise in research does not, therefore, constitute a backdoor form of critique, a way of drawing a dividing line between research which is good and research which is bad that has been implicitly leveraged by appealing to some standard of methodological purity that constrains the practice from the 'outside'. As discussed by Garfinkel and Sacks (1970), the focus on troubles is not evaluative at all, but 
descriptive: one more or less useful way of learning about what researchers do, and do routinely, as part of the work of satisfying themselves that they have been able to proceed as their chosen methods suggest. Within research practice, the question of what it might mean to follow a particular standard of 'good practice' correctly is itself an open-ended question that cannot be decided independently of the practical situations in which the question might arise with reference to the standard alone. While studies of sociological practice couched in these terms may stand at odds with (some) idealized depictions of such matters, and there is certainly a debate to be had on what exactly those depictions offer, it does not, we would suggest, clash with researchers' understanding of what it is involved in putting prescriptive accounts to work and chimes with the current interest in reorienting to 'method', not as description or prescription, picture or rule, but as something itself embedded and made perspicuous within the local forms of social and cultural practice that provide the setting for sociological research.

It is precisely these issues that we intend to take up in the empirical case studies and discussion which follow.

\section{Topicalizing method: two exemplary settings for a study of analytical work}

The examples we go on to discuss below embody the kinds of troubles researchers engaged in social scientific investigations routinely grapple with in the process of producing analyses of the social world. They also, more importantly, point to the centrality of troubles and their management to the enterprise of social research. They are drawn from a comparative observational study of the working practices of researchers located in two units within a multi-institution, interdisciplinary UK social science methods initiative explicitly set-up to encourage methodological innovation and experimentation: one group involved in qualitative research, the other in quantitative research. ${ }^{\mathrm{ii}}$ Involved in quite different disciplines and substantive areas of inquiry, the two groups had no contact prior to their involvement in the initiative and, with only limited past exposure, knew very little about the kinds of work the other was engaged in. However, having being brought together though the various collective events that were part of the initiative, members of both groups became interested in oneanother's work and, in the spirit of the wider initiative, began to discuss the possibility of collaboration. Despite this, establishing what the possible bases for collaboration could be proved difficult in the absence of an understanding of each other's research and so, based on 
what Rabinow (1996: xiii) has referred to as 'reflected curiosity', the decision was made to approach an independent group of researchers, we the authors, to undertake an ethnomethodological study of work that would offer an account of aspects of both group's methodic practices - an offer we were happy to take up.

The difficult question arises as to the possible grounds for such a comparison. We were dealing with two very different sets of research practices: one was highly mathematical and statistical in character, the other much more concerned with talk, text, artefacts and the experiences they might be said to index. There were also obvious and important 'structural' differences between the two groups: differences of disciplinary and institutional location, bibliographies, orientations, audiences, materials (instruments and data), techniques, domains of expertise, substantive topics addressed, products, forms of collaboration, organisation and management of time, resources, personnel, skills, and more besides. In terms of interpreting our instructions, thinking about these differences took us back to the aim of our study, what we could see ourselves as having been invited to do, namely, provide a description of each to the other. There were two aspects to this. Firstly, we wanted to find out what the researchers involved were trying to do and how; and secondly, we wanted to be in a position to communicate what we had been able to learn about what were quite specialized forms of research practice to those we could not assume had anything but a passing acquaintance with the kinds of research each group was doing - the position we were in before the research began. Rather than set ourselves up as authoritative interpreters, we thus saw ourselves much more as 'translators' or 'go-betweens' helping to make some aspects of the work that would otherwise remain difficult to grasp more accessible. And this, as we saw it, meant attempting to understand and describe the organization of these practices in their own terms with the researchers as our guides.

We claim no special status for our account. As one reviewer put it, we watched people at work, talked to them and read some of the work they drew on as well as produced in order to follow what was going on - quite so. Like anyone confronted with an unfamiliar activity, we sought to learn what was going on from those engaged in these activities in what are entirely unremarkable, commonplace ways - exactly the same ways in which someone who so wished could learn about our investigative practices. Our account has utility insofar as it allows others to follow those activities too - while we and those we presented the work to felt we 
managed this tolerably well, it is up to our readers to decide how successful we have been in that regard.

We were aided in this because a focus on 'methods' was a particularly visible feature of each group's work. The work of both groups was methodologically as well as substantivelyfocused and their empirical research was used for illustrative purposes to show the strengths and weaknesses of approaching particular topics in particular ways. However, these were not meta-methodological exercises but attempts to show the utility of methods-in-use, their value for particular practical research ends. In the case of the qualitative researchers, the aim was to demonstrate how a range of methods - interviewing, observation, maps, focus groups and the use of various elicitation devices (photographs, video, music, etc). - could add depth to and so enrich understandings of interpersonal relationships, particularly when used in combination. In the case of the quantitative researchers, the aim was to demonstrate that Bayesian statistical work could be used to expand the statistical techniques social scientists routinely use - allowing them to get more out of data with less. These claims were made with appropriate caveats: these were pleas for methodological pluralism rather than the superiority of any single approach, including those the researchers themselves employed. Working to a remit which explicitly topicalized questions of method, then, these units provided us with two exemplary settings for an investigation of methodological practice in social scientific work.

More specifically, and as we shall go on to discuss in more detail, the manner in which they dealt with the troubles they encountered proved particularly useful when it came to learning about what was involved in their work (for more background see Greiffenhagen, Mair and Sharrock 2011). We are not interested in evaluating how successful they were in pursuing their projects - while others will no doubt choose to draw their own conclusions, we don't see on the basis of the research we were able to conduct, how we could - but rather in developing an account of what they were doing.

Spread over five months, our research involved fifty days of fieldwork across both units, with opportunity to observe around ten working sessions involving team members in each site. We began the study at a point when the projects the units were organized around were, for the most part, already well underway. Most of the researchers involved in these projects - and there were around eight members of each team, with around four core members of full-time staff and four associate staff of varying seniority, experience and recognized areas of 
expertise - had advanced beyond data collection (or acquisition) but had not yet reached the point where they were ready to publish results. Instead, they were at the intermediate analytical stage where the priority was to work out what their research could be relevantly said to have shown.

As we had no direct access to it, we will not, therefore, talk about the process of gathering or acquiring the data. Nor, although we do have access to publications that came out of the work we were privy to, are we going to talk about published results. Our interest, instead, is in the analytical work they engaged in as part of the process of turning one into the other. We are interested, that is, in the 'alchemy' of practice (Livingston 1995), by which empirical 'data' were transformed into (and so constituted as) meaningful 'findings' and hence how something significant to a wider social science audience was leveraged from the largely unstructured textual and numerical materials the analysis began from. We are, in other words, working with an understanding of 'method' that encompasses more than simply data collection or writing but extends to a consideration of data's local 'analyzability' (Sacks 1974).

We wish to stress that there is nothing mysterious about this process. Analytical work involves embodied, material and collaborative activities that can be followed (and engaged in) by those who have gained a familiarity with the practice. It involves work on the data, rather than in the head, and so is a public and witnessable activity rather than a set of private mental operations (e.g., Coulter 1989). As a consequence, it can be seen and described. Proceeding on that basis, in what follows, we want to do just that: describe examples of analytical work, and the troubles that arose as part of it, as engaged in by the researchers whose activities we were able to observe.

We focus on two examples in particular. Each involves a different 'species' of trouble. In the first, taken from the qualitative group, the researchers grappled with problems connected to interviewee responses and, as a consequence, the open-ended interviewing practices which produced them. The second, from the quantitative group, involves the management of a data anomaly which could have raised questions about the statistical modelling work that provided the context in which the anomaly was discovered. In both cases these unforeseen problems were dealt with on an ad hoc basis, and satisfactorily for the researchers' practical purposes 
(purposes which included, importantly, anticipating the standards their work would be held to by the professional audiences to whom it would later be presented ${ }^{\mathrm{iii}}$ ).

We concentrate on these examples because they represented (momentary) disruptions to the research process which were specifically topicalized as 'troubles' by those involved, and because, in a 'reflexive' move, addressing them led the researchers involved to problematize aspects of their own 'methodic' practices. Rather than concentrate on troubles for trouble's sake, and in line with what we see as Garfinkel's original intentions, we suggest their identification and management provides insights into the wider forms of practice they became relevant as troubles within. In the course of our work, they were 'tutorial phenomena' (Garfinkel 2002) that enabled us to learn more about what doing social scientific research practically consisted in within these settings. ${ }^{\text {iv }}$ We claim no more for our account than this.

\section{Troubles with interviews}

One of the most persistently troubling aspects of interviewing, particularly open-ended, unstructured interviewing, is the (un)trustworthiness of the data it generates. Put simply, people prove unreliable as sources of information, they rarely tell it like it is - at least not in the unqualified ways that researchers might initially hope for. More often than not, researchers find interview materials trouble the 'experience-to-interview-to-text' relationship (Briggs 2007: 575), rendering straightforward mappings between them problematic. Similar kinds of questions can be asked in similar kinds of ways without those questions being answered in a consistent way, sometimes even by the same person (Suchman and Jordan 1990). Seemingly 'straight' questions, fail to elicit 'straight' answers. The 'unreliability' encountered in such cases is as much a product of the way of gathering information as it is a property of the information itself or, indeed, the informants themselves. The problems posed by interviews, in other words, are difficult to address via interviews. Faced with 'unreliable' interviews, due to the epistemological untrustworthiness of interview subjects, the problem becomes that of finding ways to locate research-relevant material within them despite the attendant problems. How this is done when a variant of this problem is encountered in practice provides the focus of our first example.

The example is taken from an analysis session involving researchers in the qualitative research group. It involved $\mathrm{L}$ and $\mathrm{C}$ who met to develop an analysis of a small corpus of 
open-ended interviews conducted as part of a larger project and who, in the process, encountered problems related to the trustworthiness of their own methods for capturing their respondents' experiences. The purpose of the study had been to explore a particular group of individuals' relationship networks over time in a residential estate on the outskirts of an English city. More specifically, it was designed to examine the negative, not just the positive, aspects of relationships with loved ones, neighbours, work colleagues and those located outside immediate kin, friendship and work circles.

Part of a broader umbrella project, comprising eight different mini-projects, the goal was to add depth to what the researchers saw as an over-simplified view of relationships in the wider sociological literature and to highlight the restricted methodological repertoire on which that view was based. Beginning with the idea that relationships, particularly over extended periods of time, can require significant investments, socially, economically and emotionally, these studies were designed to tease out what they saw as the unacknowledged personal costs of maintaining those investments. Alongside such things as happiness or contentment, this group of studies was motivated by an interest in investigating relationships as sources of ambivalence, resentment, hostility, isolation and loss and so evaluate the different senses in which lives are 'peopled'. Rather than accept the idea that relationships are straightforwardly 'good' for people, sources of 'social capital', the researchers wanted to demonstrate that people themselves, when given the chance to talk in different, more extended ways by researchers, would supply 'critical' takes on the ways in which they lived their lives with others. A specific target was a certain form of sociologically-induced nostalgia and the survey methodologies used to ground it (as in, e.g., Putnam 2000). In the case of this particular miniproject, the researchers hoped that, by gathering information across generational divides using open-ended interviewing techniques, they could show that relationships were as complicated and difficult in the past as they were in the present, thereby developing a fuller account of the realities of how lives are lived over time.

Against this broad remit, L had conducted a total of eight interviews with people of an older generation, including joint interviews with married couples about their relationships. The interviews, which lasted for around two to three hours each, were conducted in the participants' homes and L, as she reported to $\mathrm{C}$ at the start of the meeting, had been broadly satisfied when she had finished them (some months prior to this meeting) that they had provided the kinds of narrative materials they had been looking for. However, having 
revisited the interviews for the first time since conducting them, in the opening phases of the meeting L voiced her frustration that they had not provided more, mainly because they had produced what might be thought of as conspicuously 'plain' accounts of what were exactly the kinds of 'complicated' personal matters their research was predicated upon finding, and which the interview format was thought to be the perfect vehicle for gaining access to. That the interviews had failed to elicit narratives that dealt head-on with the emotional complexities of the participants' relationships was, therefore, troubling.

Working with the transcripts and pressed by $\mathrm{C}$ to supply more detail, L discussed two specific examples. One case she singled out was that of Raymond and Christine, a couple in their 80s, interviewed jointly, who had both previously been married to each other's best friends: Raymond had been best friends with Christine's husband and Christine had been best friends with Raymond's wife. Talking C through the story she was given in the interview, L explained that when their respective spouses died, they started to rely upon each other for support, and became close. When L had asked how they had moved from friendship to marriage, they explained that it seemed the most sensible thing to do.

\section{Excerpt 1}

$\begin{array}{ll}\text { I L: } & \text { So after all these years of being kind of really best friends, being the key support in each other's } \\ 2 & \text { lives, they both lost their partners. And then they got together and got married. Which is just } \\ 3 & \text { so interesting. Well it's, the (story), it's not romantic at all. They talk about it like, well, Raymond } \\ 4 & \text { was living in such and such on such and such a street, and he didn't like it cause of this. And I } \\ 5 & \text { was living } \text { [ here }^{\circ} \text { Yeah }{ }^{\circ} \\ 6 & \text { C: } \\ 7 & \text { L: }\end{array}$

In her discussion with $\mathrm{C}$ about how to make sense of Raymond and Christine's story, how to think about it for the purpose of the analysis they were trying to develop, L's suggestion (see excerpt one) was that there was, frustratingly, 'probably more to it'. Whether a 'romantic tale' was there to be told or whether Raymond and Christine's decision was a purely utilitarian one was left decidedly ambiguous and difficult to settle. As L saw it, the question of what it might mean to 'marry your dead husband or wife's best friend' was directly relevant to the research but the interview provided limited insights into possible answers. On this first reading, the value of these interview materials given the aims of the study seemed, at minimum, debatable. 
The problem of partial and incomplete testimony arose in relation to another of the interviews $\mathrm{L}$ and $\mathrm{C}$ went on to discuss. Here, however, the problems were compounded. As both $\mathrm{L}$ and $\mathrm{C}$ had independently noted prior to the meeting, the 'one big story' in this particular interview was the participant Gemma's relationship with someone called Jilly. As L and C had interpreted the interview, Gemma and Jilly had been close friends, both young mothers raising families who had fallen out over an unspecified incident (but with the strong implication of infidelity on Jilly's part) that led to Jilly leaving her husband and children and emigrating. What made the Jilly story problematic was that most of the interview with Gemma had been, from the researchers' perspective, largely uninformative in terms of the problems they had hoped it would address. Gemma had mainly volunteered truisms about the importance of family and friends, emphasizing the good and downplaying the bad - the opposite of what the researchers were looking for. As C remarked in the course of their discussion: 'she explicitly said, well, y'know I don't have that many ups and downs to talk about in terms of relationships'. However, towards the end of the interview, Gemma had introduced and had gone on to talk about her relationship with Jilly, prefacing her remarks with 'friends aren't like they used to be'. Although never made entirely explicit, their joint readings led $\mathrm{L}$ and $\mathrm{C}$ to conclude that, despite their closeness, Gemma could not tolerate Jilly abandoning her husband and children and therefore cut all ties with her.

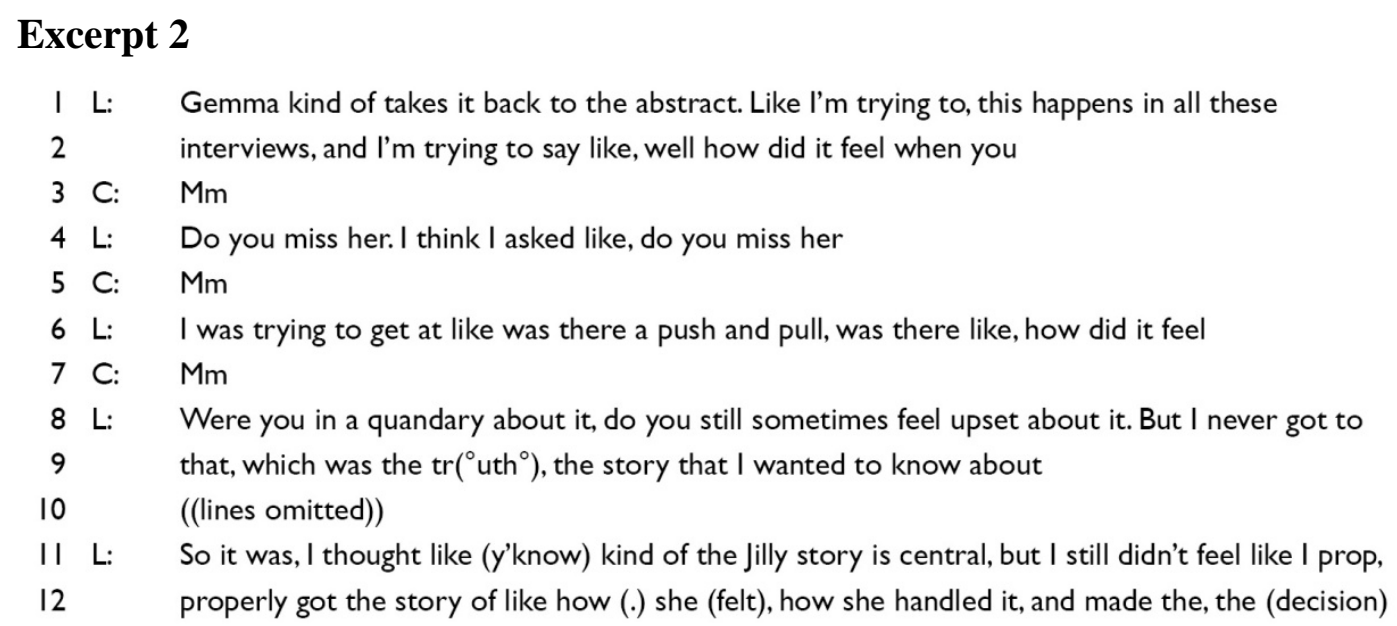

Reviewing the interview transcript, $\mathrm{L}$ and $\mathrm{C}$ noted that the Jilly story stood awkwardly against Gemma's earlier assertion that she 'never had ups and downs in her relationships'. However, this inconsistency was only part of the problem. In excerpt two above, L explains to $\mathrm{C}$ that she tried to get Gemma to talk more about Jilly but that it was not something she had found particularly easy. A little later, and in response, C commented: 'I thought you did a 
brilliant job of getting her to talk in the way she wanted to and you troubled her [...] you really did a dance around her narrative. But she was still never going to say to you, well actually, y'know, on a deep emotional level I felt $\mathrm{x}, \mathrm{y}, \mathrm{z}$ '. While this was a recognition of L's competence, it was also a restatement of the problem the interview posed: despite C's best efforts, Gemma's account was demonstrably incomplete. While the 'complicated' story came through in this case - as it had not in the interview with Raymond and Christine - the manner in which it did so gave $\mathrm{L}$ and $\mathrm{C}$ little additional scope for claiming it had done so in an unambiguous manner. Put simply, what exactly had happened and how Gemma felt about it was left vague and undefined.

What came out of L and C's observations on their first run through the transcripts was that, prima facie, the in-depth interviews thus guaranteed relevant data only haphazardly, failed to get at the crux of the particular issues they wanted to investigate and generated inconsistent, ambiguous results. These methodological troubles, troubles that have dogged the interview since it first became a staple feature of social science research (see, e.g., LaPiere 1934), were plain for the researchers to see. However, the very manner in which these troubles were posed also provided them with materials for dealing with them.

In the rest of the session, as the researchers moved beyond the troubles their first readings had revealed, they began to piece together a solution that would enable them to use these materials to make their case. Rather than undermining the research process, they saw a way of treating the presence of these issues as affirming the value of the data they had gathered rather than the data they might conceivably have been said to have missed. Indeed, as their discussion continued, the fact that their interviews contained absences and inconsistencies came to be seen as making them especially rich for their purposes. Instead of treating the accounts they were given as incomplete, in a neat reversal, the researchers saw that they could be treated as expressions of the very phenomenon they were interested in exploring namely, the ambiguities and sensitivities that surround our intimate relationships and the difficulties we face in talking frankly about them. In this way, the very 'weaknesses' a first reading and the initial discussion exposed became measures of the 'strength' of the methods they had employed - a move accomplished by shifting the locus of analytical interest from Raymond, Christine and Gemma's relationships themselves to their ways of accounting for those relationships. 
In working out ways of making do with these materials despite the methodological troubles they posed, L and C concluded that it was because of those troubles that the interviews provided them with what in fact they had been looking for all along. In this way, the practical process of locating and determining the troubles their work had given rise to furnished the researchers with the means to resolve and move past them in ways they were satisfied would prove of interest to the audiences the results of this analytical work would be presented to. It was, therefore, in these ways of working through the data that the interviews as 'methods' could be treated as producing research-relevant findings.

\section{Troubles with models}

Methodological troubles are not just a feature of qualitative research they also plague quantitative research - the focus of our second case. Despite being organized, drilled and disciplined in various ways, the data processed by statisticians' models may nonetheless refuse to tell the desired analytical story as and when required. Instead, difficult to diagnose glitches, inconsistencies and anomalies emerge which interfere with the presentation of results. Lakatos (1976) suggested that a typical first step when confronted with methodological troubles of this kind is to simply 'bar the monster[s]' from the outset, i.e., to find a way of proceeding that obviates the need to consider them at all (see also Woolgar 1988; Star and Gerson 1987). In what follows, we pick up this second troubling methodological theme, and examine the ways in which the manner of their appearance provides resources for ensuring they can be kept safely out of view.

The example is taken from our work with the second of the two units we studied, the unit involved in quantitative data analysis (see also Mair, Greiffenhagen, and Sharrock forthcoming). While working with social scientists, the researchers working in this unit defined themselves as statisticians and had backgrounds in formal rather than substantive disciplines, i.e. disciplines like mathematics and bioinformatics. As is the case with statisticians more generally, their involvement in primary data collection was limited. Instead, their work typically began after surveys had been conducted, data entered and databases constructed, when they were called in to do the calculative work needed to ascertain and exploit the deeper 'affordances' of these complex numerical artefacts. They were involved in four main projects, each designed to find ways of bringing advanced statistical modelling techniques to bear on methodological problems within the social sciences (i.e. longitudinal 
analysis, spatio-temporal comparison, data synthesis and bias estimation), and they used a range of 'applications' (i.e. datasets relating to a range of phenomena selected on the basis of characteristics that made them especially suitable for the task at hand) as test-grounds for the statistical 'tools' they were seeking to develop.

The trouble we shall focus on arose as part of one of these projects: modelling for spatiotemporal comparison. As part of this project, the researchers wanted to take data on temporal changes in the frequency of such things as, for example, cases of a specific illness over time, and combine it with data on the spatial distribution of cases of that illness in order to trial and showcase their modelling techniques. Their models were being designed in such a way that they would allow the identification of general trends from year to year across all the areas their data covered, but with a capacity not only to identify particular areas which deviated from the general trend but also to enable them to specify by how much. Though the model was designed to be general purpose, its development had been based on work with specific datasets, one of which contained data on cases of chronic obstructive pulmonary disease (COPD) across the different regions of the UK. The models under construction were tested using the datasets to check whether they produced the expected results.

Unlike the previous case, the meeting that we concentrate on took place in the closing stages of this particular project. The two researchers involved, $\mathrm{J}$ and $\mathrm{M}$, had been working on the general problem as well as the substantive applications for some time and the purpose of the meeting was to determine whether the model they had built could be 'finalized' and written up for publication. In their immediately prior meeting (one we also attended) some aspects of the model had been questioned, and one of the researchers $(\mathrm{J})$ had undertaken significant work to refine it in response. The two were meeting to sign off this work, and agree that they could now proceed to the applications rather than undertake any further specifically modelrelated work. J, as the researcher on the project, had made sure $M$ had been sent results of the testing he had been doing well in advance of the meeting, and the discussion centred on what he thought the various graphs and plots he had produced showed. Before getting into that, however, J offered a summary of what he had done - noting, as he did so, a trouble that had arisen between the last meeting and this. 


\section{Excerpt 3}

I J: Um, l've been working on thee um (.) well putting some of the models in action (.) the final

2

$3 \mathrm{M}: \quad\left[\begin{array}{l}\text { Okay, yep } \\ \text { Okn }\end{array}\right.$

$4 \mathrm{~J}$ : (Well um l'm) using the COPD data for eight years. But I changed from ten years previously

$5 \mathrm{M}$ :

Mm hmm

6 J: I said um we use, going to use ten years, but not ten years because I use um, eight years for

$7 \quad$ simulation so its

8 M: Yeah, it's difficult (inaudible), yeah, fine. Yeah

9 J: (A kind of different distribution). So now it's eh from 90 to 97

$10 \mathrm{M}: \quad$ Yeah

II J: So um it's (inaudible) the change in 92 , policy (.) Um, okay. So l'm going to show you some

12 results of applying one of the final models. To this dataset

In this excerpt, $\mathrm{J}$ starts by saying that the materials he is about to go through on the computer show the final models 'in action', i.e., applied to the COPD data. For the researchers, one of the model's main 'selling points' in terms of applications (as opposed to the statistical accomplishment of combining spatial and temporal data 'robustly') was that it could be used to detect policy effects. What made the COPD data particularly useful in this regard was that it covered a period which included a change of legislation in 1992 when the rules covering who could qualify for compensation for work-related COPD were relaxed, making it easier for those who had contracted COPD through their work (miners, for example) to claim financial support. Given the added financial incentives associated with a confirmed diagnosis of COPD, the researchers wanted to see if there was a spike in cases at any time post-1992 in areas where work-related COPD had historically been a particular issue (mining communities, for example) as people sought medical certification in order to qualify for compensation. The policy change in 1992 was, thus, an 'event' the researchers suspected would impact differently on disease trends in specific areas and so could be used to both calibrate and demonstrate the capabilities of their model. Prior to this meeting, they had been looking at changes across a twenty year period, using two ten-year datasets (from 1990 to 1999 and 2000 to 2009), but in excerpt one J explains that he had to change this to a sixteen year period, using two eight year datasets (from 1990 to 1997 and 1998 to 2005), due to a difficulty he had encountered, something $M$ at this stage seems to accept. Later in the session, however, the same issue came up again, with $\mathrm{M}$ asking $\mathrm{J}$ for much more detail: 


\section{Excerpt 4}

I J: And when there's, well, another reason for switching to the (8 years) data is, uhm, it gives, kind

2 of, better convergence

$3 \quad(($ lines omitted))

4 M: Yeah

$5 \mathrm{~J}$ : After 40,000 iterations and everything's fine

$6 \mathrm{M}: \quad$ Yeah

$7 \mathrm{~J}$ : Don't have the non-convergence for the (p?) values, heh, so

$8 \mathrm{M}$ : Which is good

$9 \mathrm{~J}$ : Heh, which is better, heh

$10 \mathrm{M}$ : Maybe there's something a bit odd in the data for one of those final two years, when you're II looking at ten years

$12 \mathrm{J:}$ (inaudible)

13 M: I can't see any reason heh why it should be fine for 8 years and not let you add any more in 14 general (inaudible)

$15 \mathrm{~J}$ : Well, I mean, this, this is fine for 8 years, from 90 to 97 . Then when I use 99 to 06

$16 \mathrm{M}: \mathrm{Mm}$

$17 \mathrm{J:} \quad$ Previous, previous version. That was fine too

$18 \mathrm{M}: \mathrm{Mm}$

$19 \mathrm{~J}$ : With the BYM and CAR

$20 \mathrm{M}$ : Lokay

$21 \mathrm{~J}$ : Which is when I have 10 years ((sucks in breath))

22 M: ((Smiles, laughs)) Heh, heh

$23 \mathrm{~J}$ : Okay, heh ((smiling, laughs)) Now, that's fine. Eh, with, with the BYM and CAR I just extract,

24 well I estimate::ed, the eh common spatial and common temporal

25 M: Yeah

$26 \mathrm{~J}$ : I used those two terms ((oblique reference to what is on screen)) to do the simulation to get

27 the eh, the FDR estimate

28 M: Yeah, yeah

$29 \mathrm{~J}$ : For the cut-offs. So that's the eh convergence (there) ((oblique reference to what is on screen,

30 indexed by moving onto the next slide)). And that's the time-pattern for these, em, 8 years

3। M: Okay

While J's revised 'time pattern' still covered the 1992 policy change and a significant period afterwards, the problem was that, in principle, the model ought to have worked with any stretch of data. Decades are merely conventional units for marking time and are largely selected for aesthetic rather than formal reasons. However, elaborating on the difficulty first hinted at in excerpt 1, in excerpt $2 \mathrm{~J}$ explains that he discovered a 'non-convergence' problem when he tried to use one of the ten-year datasets they had been using up till then (1990-1999) with the new models (i.e., the algorithm did not come to an end, but ran on indefinitely without completing its computational task). When he switched to using the two eight-year datasets, however, things worked perfectly well. The ten year span may have been considered preferable on conventional grounds, but the results of running numerous tests on the data 
with the models had shown everything else was as it should have been and, indeed, had been before.

Although the 'fix' worked, it did not do quite enough to satisfy M, who questioned J further. One of M's suggestions was that there might have been a problem with the data for the additional two years (line 10). The problem was she could not work out why this might have been the case (line 13). In order to understand what might have bothered $\mathbf{M}$, it is worth setting out the formal characteristics of this trouble in more detail, putting it in the context of the history of the project more broadly. Schematically, we can present things as follows:

Figure I: Overview of the research process

\begin{tabular}{|l|l|l|l} 
& Phase 1 & Phase 2 & Phase 3 \\
\hline Model & Initial Model & Intermediate Model & Final Model \\
\hline Data & $10+10$ years & $10+10$ years & $8+8$ years \\
\hline
\end{tabular}

Figure I breaks the research process down into two parallel streams of activity: the work on the model and the work on the application. The work on the models had gone through three iterations: it began with an initial model, it proceeded through a whole series of more and more refined intermediate models, and it culminated in the final model (or set of models), ready to be presented to a professional audience. In parallel with each of the stages, a process covering around a year and a half, the models had been tested with ten year stretches of data, taken from the COPD and other 'model' datasets, without any problems whatsoever. It was only after the final changes had been made to their model that the non-convergence problem arose. Just as the logic underpinning the model had been settled to the satisfaction of both $\mathrm{J}$ and $\mathrm{M}$, this application (but not others) had been thrown out of kilter.

The presence of a 'non-convergence' problem around the ten-year span might conceivably have led to questions about other elements of their work, potentially raising doubts about their hardware, the bespoke statistical programmes they were using or even the proper functioning of the model itself. The failure to process a data-set the model ought to have been able to cope with perfectly adequately might therefore have been used to open up a modelling process the researchers now considered closed (see here Latour and Woolgar 1979: 77-85). 
However, the issue, as such, was not seriously entertained. They had isolated a component which, when reconfigured, led their statistical apparatus to behave as it had done before. The question as to whether it was the data, the programming and code or the new features of the model that was causing the problem was not categorically settled. There was no need. The work-around solution of 'running' two smaller data-sets together (see Figure II) rather than two slightly larger ones was seen as sufficient, and in the meeting they both agreed that there was no reason for thinking, given that it did work, that there might be something wrong elsewhere. From what they could see, nothing important to the modelling hinged on the data's anomalous behaviour: the model would neither stand nor fall on the basis of what to all extents and purposes looked like a glitch. Given that they had a fix, an inelegant one but a solution nonetheless, the investigators were thus happy to move forward on the basis that if they were to look into the matter further, anomalies would turn up in the 1998-1999 data when processed within a ten-year dataset. That they could proceed was enough, then, for them to proceed, with the 16 year span sufficient to demonstrate the capabilities of the model.

\title{
Figure II: Some different ways of adding time
}

\author{
10-Year Blocks \\ possibility (a): 1980-1989 + 1990-1999 + 2000-2009 + ... \\ possibility (b): 1981-1990 + 1991-2000 + 2001-2010 + ...
}

\section{8-Year Time Blocks}

$1990-1997+1998-2005+2006-2013+\ldots$

What we have here, then, is another instance where the methodic and conscientious application of a 'method' to 'data' generates inconsistent results (a model that could run over two eight-year datasets but not two ten-year ones), but where the process of diagnosing the trouble also pointed the way to a practically adequate remedy (running two smaller stretches of data together). Faced with the non-convergence problem with the ten year dataset, $\mathrm{J}$ wanted to see whether it worked with less data, an eight-year dataset, and it did: diagnostic and solution are here one and the same. J's subsequent reassurances regarding the tests he had run were enough to convince $M$ that it was the data (in a way that did not need to be specified or indeed investigated further) which was problematic. Had the fix not worked, there would 
have been a problem. It did work, however, and, although the problem was not resolved, they could move on.

We see this example as a counterpart to the previous case-study. The major difference between the two cases is that, whereas the researchers in the first case proceeded by foregrounding problems with their methods, recasting them as strengths, in this case the researchers worked to make sure potential frailties need not have to be given serious consideration. As Garfinkel put it, there are 'practices for locating monsters but there are also practices for burying them' (Hill and Crittenden 1968: 213). What we would like to point out, following Garfinkel, is that monster-burying is not a matter of 'epistemological deception', of deluding oneself or others. Rather, and in line with the arguments we have presented thus far, these ad hoc resolutions are what allow researchers to address problems as and when they arise and so make their methods work and, from there, their results count.

\section{Conclusion}

In the course of the Purdue Symposium on Ethnomethodology (Hill and Crittenden 1968), Garfinkel became involved in a series of tetchy exchanges with the non-ethnomethodologists who had convened to find out more about what ethnomethodology might have to say to them. One of those exchanges was with the survey researcher David Gold:

$\begin{array}{ll}\text { Gold: } & \text { [W]e have methods by which we can determine ... an unreliable } \\ \text { Gesponse or a systematically untrue response ... } \\ \text { Quite right! No question! The thing I keep getting back to } \\ \text { however ... is how the work actually gets done. That is the only } \\ \text { thing of interest. That it is a practical kind of activity is the thing } \\ \text { that is of interest ... There are rules of good procedure, of course. } \\ \text { We relax those rules; nevertheless, though they were relaxed, the } \\ \text { rules will have been counted as having been followed. That is a } \\ \text { phenomenon. Ethnomethodologically, that is a phenomenon. } \\ \text { (Hill and Crittenden 1968: 193-198) }\end{array}$

This response by Garfinkel, like a later remark in which he suggests an equivalence between the methods of social research and the methods of Zande divination, is certainly provocative. However, it is not merely provocative. What Garfinkel highlights is that for ethnomethodology the interest is that the work gets done in spite of attendant problems and, as a consequence, the focus becomes investigating how this is accomplished. Garfinkel is not asserting the impossibility of social science, but rather pointing to an alternative conception 
of what it consists in, one in which 'social science practice' is not determined by, or coextensive with, 'rules of good procedure'. That is not to say 'rules of good procedure', i.e. methods, have no relevance in social science, but, rather, that they should not be treated as decontextualised descriptions of research practice - where one substitutes for the other. Instead, as we have tried to show, their relation to research practice is contingent, they are invoked and brought into play locally, 'for all practical purposes', by researchers in the course of what they do and in the course of the troubles they encounter along the way.

We believe it is important to return to these ethnomethodological concerns because attending to methodological troubles and their management, to our minds, helps clarify what it could mean to talk about 'methods' as practical features of social scientists' work. In treating methods as social and cultural phenomena in and of themselves, with their own biographies and 'personal' entanglements - as in discussions of the history of the survey, the interview, the focus group, and so on - we see a danger that the recent 'empirical studies' of social science methods may encourage 'methodological hagiography', with the history of social science rewritten, no longer as the lives of 'great men', but as the lives of 'great methods' (whether heroic, villainous or otherwise, see e.g. Law 2009; Majima and Moore 2009; Law, Ruppert and Savage 2011; Savage 2013). The examples we have chosen to examine in this article allow us to see why granting autonomy to method, a contemporary reworking of the mythological conception of the methodology of the social sciences (with the focus not on the significance of the researcher but the techniques they employ), is liable to end up in confusion. This is because the existence of troubles, and the fringe of ad hoc practices that they extend out into, call into question the idea that there is any fixed 'thing' - the method to write a biography of. Put slightly differently, we agree that social scientific research practices constitutes a legitimate domain of inquiry, we just don't agree, following Garfinkel, that taking references to the centrality of methods within those practices at face value represents a good way of proceeding to examine it.

The examples we examined were taken, quite deliberately, from familiar research situations discussions between researchers about how to analyse data - settings which require little explanation or prior tutelage to grasp (see Lynch 1993). Despite the fact, to borrow from Anderson and Sharrock, that '[there] is nothing difficult or arcane in them', the 'trivialness of the examples should not mislead us into thinking that the practices they evince are trivial, for they are not' (Anderson and Sharrock 1993: 150). Instead, as we hope their familiarity 
underscores, the troubles they 'evince' are the very stuff of methodical research practice in the social sciences. As such they provide us with insights into the wider working contexts such troubles acquire their salience within, namely research as a practical enterprise centred on arriving at analyses which are 'good enough' - contrary to what many think, a far from trivial matter.

The failure to take account of the open texture of practices within which 'methods' acquire their abidingly troubled salience for social research means the picture we have of them is necessarily incomplete. What Garfinkel insisted on was that methodological troubles are not inconvenient problems, they are the phenomenon, central to determining what talk of 'method' could possibly mean in the local context and developing historicity of researchers' work together. It is researchers' ad hoc invocations of shared understandings, relative to their background knowledge of the 'social structures' they are investigating and, crucially, the social organization of their own inquiries, including the wider requirements their analyses must demonstrably meet and the competences they must demonstrably display, that enable them to satisfy themselves that they have correctly identified how things are - both where their procedures have been deemed to be satisfied and where they have been deviated from for 'good reasons'. Insofar as social studies are treated as accounts of empirical features of the social world, then the capacity of any method to yield this is achieved in and over the course of the inquiry, unavoidably in and through its specifics.

We believe this comes across strongly in our cases and we hope we have adequately conveyed the footwork required to resolve the troubles and move on in each case. In finding ways of dealing with their problems, problematic interviews and misbehaving data, both sets of researchers ended up clarifying what they were after all along: not complete descriptions of personal relationships or pleasing graphs of decades of change, but an analysis of the difficulties people have in talking about their relationships and the differential effects of policy changes across space and time. In neither case was the research compromised, we would suggest, but strengthened, in the researchers' own terms, as a result of encountering troubles. Moreover, and this is perhaps the nub of the matter, it was precisely the manner of the appearance of the troubles they encountered that provided the researchers with the means for overcoming them. Understanding analytical work and methods work more broadly, then, hinges upon, and in determinate ways, an understanding of the troubles it is intertwined with. The exchange from the Purdue Symposium encapsulates the shift in perspective involved in 
orienting to troubles in this way: while Gold sees troubles as methodological problems, Garfinkel sees them as internal to sociological inquiries, the normal troubles of investigative work.

Based upon the above, we might say that the idea that sociological inquiries rest upon methods and associated doctrines is a way of talking that glosses the capacity of sociologists to speak of factual states in the social world, one which is associated with a thoroughly practical - but largely almost entirely unofficial - understanding of the practical organizational conditions that govern in situ determinations of what can (as concretely as possible) be said about what has been found, observed, understood, etc. Two further points emerge from this. Firstly, it is an illustration of Garfinkel's analysis of compliance with general procedures in specific settings: namely, that the demands of the present situation always take priority in decisions about how general procedures are to be applied. And, secondly, the realization of this fact in actual research practice does not instantiate 'bad practice' or in any way - additional to those that might trouble researchers themselves invalidate what they do. Rather, it only reinforces Garfinkel's central contention, that such prioritizing is not a setback but merely a realistically necessary feature of getting research done at all.

While research is not a free for all where anything goes, we do not think much progress has been made in terms of getting to its organization in practical settings. As set out here, we think orienting to troubles is one way in which that could be profitably pursued. This brings us to what we regard as the central difference between ethnomethodological studies of method in the social sciences and the more recent body of science and technology inspired studies. Unlike the laboratory studies of the 1980s, to which ethnomethodology and, for instance, actor-network theory, made such distinctive contributions (Lynch 2011), current work on social science methods has not retained the focus on in-depth studies of hands-on research practice, instead treating accounts of methods as proxies for those practices. The ethnomethodological focus on troubles is salutary in this regard as it demonstrates that there is always more to research practice than such accounts allow. If studies of social science methods are to illuminate the practices they speak of, we suggest that the question largely lacking a sociological answer is not 'what is the role of sociology's methods in the wider society?' but 'what is the actual role of sociology's methods in sociology?' 


\section{Acknowledgements}

This research was made possible by the ESRC through funding to the NCRM, project code RES-576-25-0022. We would like to thank the researchers in both units that we studied for their time, patience, and generosity in facilitating our study. Thanks are also due to the editor and the anonymous reviewers for their helpful comments on the article.

\section{Bibliography}

Abbott, A.D. 2001 Chaos of Disciplines, Chicago, IL: Chicago University Press.

Anderson, R. J. and Sharrock, W. W. 1993 'Can Organisations Afford Knowledge?', Computer Supported Cooperative Work (CSCW) 1(3): 143-161.

Antaki, C., Biazzi, M., Nissen, A. and Wagner, J. 2008 'Accounting for Moral Judgments in Academic Talk: The Case of a Conversation Analysis Data Session', Text and Talk 28(1): $1-30$.

Atkinson, P. 1988 'Ethnomethodology: A Critical Review’, Annual Review of Sociology 14: 441-465.

Benzecry, C.E. and Krause, M. 2010 'How Do They Know? Practicing Knowledge in Comparative Perspective', Qualitative Sociology 33(4): 415-422.

Bergman, M. M. (ed) 2008 Advances in Mixed Methods Research: Theories and Applications, London: Sage.

Bourdieu, P. and Wacquant, L. 1992 An Invitation to Reflexive Sociology, Cambridge: Polity Press.

Briggs, C. L. 2007 'Anthropology, Interviewing, and Communicability in Contemporary Society', Current Anthropology 48(4): 551-580.

Bryman, A. 1988 Quantity and Quality in Social Research, London: Unwin Hyman.

Bushnell, C. 2012 'Talking the Talk: The Interactional Construction of Community and Identity at Conversation Analytic Data Sessions in Japan', Human Studies 35(4): 583605.

Camic, C., N. Gross, and Lamont, M. (eds) 2011 Social Knowledge in the Making, Chicago: University of Chicago Press.

Greiffenhagen, C., M. Mair, and W. Sharrock (forthcoming). Methodological troubles as problem and phenomenon: Ethnomethodology and the question of 'method' in the social sciences. Forthcoming British Journal of Sociology. 
Cicourel, A.V. 1964 Method and Measurement in Sociology, New York, NY: The Free Press.

Coulter, J. 1989 Mind in Action, Cambridge: Polity.

Espeland, W. N. and Stevens, M. L. 2008 'A Sociology of Quantification', European Journal of Sociology 49(3): 401-436.

Gane, N. 2012 'Measure, Value and the Current Crises of Sociology', in L. Adkins and C. Lury (eds) Measure and Value, London: Wiley-Blackwell.

Garfinkel, H. 1967 Studies in Ethnomethodology, Englewood Cliffs, NJ: Prentice-Hall.

Garfinkel, H. 2002 Ethnomethodology's Program: Working Out Durkheim's Aphorism, Lanham, MD: Rowman \& Littlefield.

Garfinkel, H. and Sacks, H. (1970) 'On Formal Structures of Practical Actions', in J.C. McKinney and E. Tiryakian (eds) Theoretical Sociology (pp. 338-366), New York, NY: Appleton-Century-Crofts.

Garforth, L. 2012 'In/visibilities of Research: Seeing and Knowing in STS'. Science, Technology and Human Values 37(2): 264-285.

Gieryn, T. 2006 'City as Truth-spot: Laboratories and Field-sites in Urban Studies', Social Studies of Science 36 (1): 5-38.

Goodwin, C. 1994 'Professional Vision', American Anthropologist 96(3): 606-633.

Greiffenhagen, C. 2008 'Video Analysis of Mathematical Practice? Different Attempts to “Open Up” Mathematics for Sociological Investigation', Forum: Qualitative Social Research 9(3).

Greiffenhagen, C. 2014 'The Materiality of Mathematics: Presenting Mathematics at the Blackboard', British Journal of Sociology 65(3), 502-528.

Greiffenhagen, C., Mair, M. and Sharrock, W. W. 2011 'From Methodology to Methodography: A Study of Qualitative and Quantitative Reasoning in Practice', Methodological Innovations Online 6(3), 93-107.

Gupta, A. and Ferguson, J. (eds) 1997 Anthropological Locations: Boundaries and Grounds of a Field Science, Berkeley, CA: University of California Press.

Hill, R. J. and Crittenden, K. S. (eds) 1968 Proceedings of the Purdue Symposium on Ethnomethodology, Purdue, IN: Institute for the Study of Social Change. Available at https://aiemcanet.files.wordpress.com/2010/07/purdue.pdf

Greiffenhagen, C., M. Mair, and W. Sharrock (forthcoming). Methodological troubles as problem and phenomenon: Ethnomethodology and the question of 'method' in the social sciences. Forthcoming British Journal of Sociology. 
Housley, W. and Smith, R. J. 2011 'Telling the CAQDAS Code: Membership Categorization and the Accomplishment of 'Coding Rules' in Research Team Talk', Discourse Studies 13(4): 417-434.

Hutchinson, P., Read, R. and Sharrock, W. W. 2008 There is No Such Thing as a Social Science: In Defence of Peter Winch, Aldershot: Ashgate.

Jordan, B. and Fuller, N. 1975 'On the Non-fatal Nature of Trouble: Sense-making and Trouble-managing in Lingua Franca Talk’, Semiotica 13(1): 11-31.

Konopásek, Z. 2008 'Making Thinking Visible with Atlas.ti: Computer Assisted Qualitative Analysis as Textual Practices’, Forum: Qualitative Social Research 9(2): Article 12.

Lakatos, I. 1976 Proofs and Refutations: The Logic of Mathematical Discovery, Cambridge: Cambridge University Press.

Lamont, M. 2009 How Professors Think: Inside the Curious World of Academic Judgment, Cambridge, MA: Harvard University Press

Latour, B. and Woolgar, S. 1979 Laboratory Life: The Social Construction of Scientific Facts, Beverley Hills, CA: Sage.

LaPiere, R. T. 1934 ‘Attitudes vs. Actions’, Social Forces 13(2): 230-237.

Law, J. 2009 ‘Seeing Like a Survey’, Cultural Sociology 3(2): 239-256.

Law, J., Ruppert, E. S. and Savage, M. 2011 'The Double Social Life of Methods', Working Paper No. 95, ESRC Centre for Research on Socio-Cultural Change (CRESC).

Leahey, E. 2008 'Methodological Memes and Mores: Toward a Sociology of Social Research', Annual Review of Sociology 34: 33-53.

Livingston, E. 1995 An Anthropology of Reading, Bloomington, IN: Indiana University Press.

Lury, C. and N. Wakeford (eds) 2012 Inventive Methods: The Happening of the Social, London: Routledge

Lynch, M. 1985 Art and Artifact in Laboratory Science: A Study of Shop Work and Shop Talk in a Research Laboratory, London: Routledge and Kegan Paul.

Lynch, M. 1993 Scientific Practice and Ordinary Action: Ethnomethodology and Social Studies of Science, Cambridge: Cambridge University Press.

Lynch, M. 2000 'The Ethnomethodological Foundations of Conversation Analysis', Text 20(4): 517-532.

Lynch, M. 2011 'Harold Garfinkel (29 October 1917 - 21 April 2011): A Remembrance and Reminder', Social Studies of Science, 41(6): 927-942.

Greiffenhagen, C., M. Mair, and W. Sharrock (forthcoming). Methodological troubles as problem and phenomenon: Ethnomethodology and the question of 'method' in the social sciences. Forthcoming British Journal of Sociology. 
Mair, M., Greiffenhagen, C. and Sharrock, W. W. 2013 'Social Studies of Social Science: A Working Bibliography', NCRM Working Paper Series, No. 3219. Available at http://eprints.ncrm.ac.uk/3219/

Mair, M., Greiffenhagen, C. and Sharrock, W. W. forthcoming 'Statistical Practice: Putting Society on Display', Theory, Culture \& Society. Available at http://dx.doi.org/10.1177/0263276414559058

Majima, S. and Moore, N. 2009 'Introduction: Rethinking Qualitative and Quantitative Methods', Cultural Sociology 3(2): 203-216.

Maynard, D.W. and Schaeffer, N. C. 2000 'Toward a Sociology of Social Scientific Knowledge: Survey Research and Ethnomethodology's Asymmetric Alternates', Social Studies of Science 30(3): 323-370.

Maynard, D. W., Houtkoop-Steenstra, H., Schaeffer, N. C. and van der Zouwen, J. (eds) 2002 Standardization and Tacit Knowledge: Interaction and Practice in the Survey Interview, New York: Wiley.

Olszewski, B., Macey, D. and Lindstrom, L. 2007 'The Practical Work of Coding: An Ethnomethodological Inquiry’, Human Studies 29(3): 363-380.

Osborne, T. and Rose, N. 1999 'Do the Social Sciences Create Phenomena? The Example of Public Opinion Research’, British Journal of Sociology 50(3): 367-396.

Osborne, T. and Rose, N. 2004 'Spatial Phenomenotechnics: Making Space with Charles Booth and Patrick Geddes', Environment and Planning D 22(2): 209-228

Osborne, T., Rose, N. and Savage, M. (eds) 2008 Special Centenary Issue: 'Inscribing the History of British Sociology', Sociological Review 56(4).

Putnam, R. 2000 Bowling Alone: The Collapse and Revival of American Community, New York, NY: Simon and Schuster.

Rabinow, P. 1996 Essays on the Anthropology of Reason, Princeton, NJ: Princeton University Press.

Roulston, K., DeMarrais, K. and Lewis, J. B. 2003 'Learning to Interview in the Social Sciences’, Qualitative Inquiry 9(4): 643-668.

Ruppert, E. S. 2007 'Producing Population', Working Paper No. 37, ESRC Centre for Research on Socio-Cultural Change (CRESC).

Sacks, H. 1974 'On the Analyzability of Stories by Children', in R. Turner (ed) Ethnomethodology, Harmondsworth: Penguin.

Sacks, H. 1992 Lectures on Conversation, Oxford: Blackwell.

Greiffenhagen, C., M. Mair, and W. Sharrock (forthcoming). Methodological troubles as problem and phenomenon: Ethnomethodology and the question of 'method' in the social sciences. Forthcoming British Journal of Sociology. 
Saetnan, A. R, Lomell, H. M. and Hammer, S. (eds) 2011 The Mutual Construction of Statistics and Society, London: Routledge.

Savage, M. 2010 Identities and Social Change in Britain since 1940: The Politics of Method, Oxford: Oxford University Press.

Savage, M. 2013 'The Social Life of Methods: A Critical Introduction’, Theory, Culture \& Society 30(4): 3-21.

Savage, M. and Burrows, R. 2007 'The Coming Crisis of Empirical Sociology', Sociology 41(5): 885-899.

Sharrock, W.W. 2001 'The Fundamentals of Ethnomethodology’, in B. Smart and G. Ritzer (eds) Handbook of Sociological Theory, London: Sage

Silverman, D. 1973 'Interview Talk: Bringing off a Research Instrument', Sociology 7(1): 31-48.

Star, S. L. and Gerson, E. M. 1987 'The Management and Dynamics of Anomalies in Scientific Work’, Sociological Quarterly 28(2): 147-169.

Stark, L. 2011 Behind Closed Doors: IRBs and the Making of Ethical Research, Chicago, IL: University of Chicago Press

Suchman, L. and Jordan, B. 1990 'Interactional Troubles in Face-to-face Survey Interviews', Journal of the American Statistical Association 85(409): 232-241.

Tutt, D. and Hindmarsh, J. 2011 'Reenactments at Work: Demonstrating Conduct in Data Sessions', Research on Language and Social Interaction 44(3): 211-236.

Wittgenstein, L. 1953 Philosophical Investigations, Oxford: Basil Blackwell.

Woolgar, S. 1988 Science: The Very Idea, Chichester: Ellis Horwood.

Greiffenhagen, C., M. Mair, and W. Sharrock (forthcoming). Methodological troubles as problem and phenomenon: Ethnomethodology and the question of 'method' in the social sciences. Forthcoming British Journal of Sociology. 
${ }^{\mathrm{i}}$ We do not wish to suggest that ethnomethodology is or ever was a neatly unified field of inquiry. There are, for example, important differences between the positions of Garfinkel (1967), Sacks (1992) and Cicourel (1964) as well as subsequent ethnomethodologists and conversation analysts. Cicourel's work, for instance, was partly predicated on developing a programme that would, on an interventionist footing, seek to positively address the methodological problems that beset the social sciences. Garfinkel and Sacks, by contrast, stressed their 'indifference' to resolving sociology's unending troubles with method (Garfinkel and Sacks 1970). For Garfinkel and Sacks, those troubles were topics to be studied not problems to be remedied practically, methodologically or theoretically (see Lynch 1993). At the same time, however, neither Garfinkel nor Sacks pursued investigations of sociological practice in the same way. While we concentrate on Garfinkel's position here, it would not do to overplay the differences either. There are recognizable continuities in play too and anyone interested in ethnomethodology's long-running concern in social scientific practice, an interest which has given rise to all manner of studies over time, will doubtless find many lines of 'family resemblance' (Wittgenstein 1953) running through the large body of empirical studies of sociological practice that have been conducted by ethnomethodologists since the 1960s (see Mair, Greiffenhagen and Sharrock 2013).

ii We have no intention of scoping the state of quantitative, qualitative and mixed methods here (see, e.g., Bryman 1988; Bergman 2008). We would note, however, that discussion of those issues has been largely programmatic (even where programmatics have been disavowed, see e.g. Gane 2012; Savage 2013), divorced from a consideration of the sites, settings and disciplinary situations in which qualitative and quantitative researchers ply their trades - our primary concern in this article.

iii We do not deny that researchers' work is held to particular standards and they orient to those standards within their work. How their peers would receive their work was undoubtedly a major consideration in the cases we examined - they reminded each other of this while doing their work. However, the standards that might be said to be demanded of them had to be worked out in relation to the courses of inquiry they were actually engaged in as they engaged in them. There was, as it were, no pre-formulated, inquiry-independent protocol that could be appealed to for an answer to that question. Working out what was expected of them in terms of 'standards of good practice' was not fixed but itself determined in the course of what they did before they engaged with wider audiences.

iv In line with what we saw as the remit of our study, we presented these examples to the researchers in both groups. Although we were asked to anonymize these cases, both sets of researchers were relaxed about the focus on troubles in the broad and our description of these troubles in the narrow, acknowledging their presence as features of the research process. Anonymity was not requested because the researchers felt there was anything to hide but because of overlaps between the data we examine here and data examined in publications from the projects, something the researchers involved felt might lead to confusion.

Greiffenhagen, C., M. Mair, and W. Sharrock (forthcoming). Methodological troubles as problem and phenomenon: Ethnomethodology and the question of 'method' in the social sciences. Forthcoming British Journal of Sociology. 